\title{
QUANDO A EDUCAÇÃO CIVILIZA: PROPOSIÇÕES SOBRE A ESCOLA RURAL PEDRO II (PARÁ, ANOS DE 1860)
}

\author{
Francivaldo Alves Nunes ${ }^{2}$
}

\section{RESUMO}

A proposta deste texto é analisar o processo de implantação da escola rural D. Pedro II, estabelecida na fazenda provincial Pinheiro, nas proximidades de Belém, como um dos grandes "feitos" do governo paraense, quando se tratava do desenvolvimento e futuro próspero da agricultura na região amazônica e no que se convencionou chamar de "civilização dos hábitos rurais". Esta instituição de ensino marcava um embate entre as ações costumeiras dos colonos e os discursos de civilidade empreendidos pelo governo provincial, que tinha na própria estrutura administrativa da escola seus representantes mais diretos. Assim, a escola era utilizada como instrumento de defesa de valores e interesses do governo provincial, uma vez que as proposições para este espaço posicionava esta instituição de ensino agrário para divulgação de ideias quanto a superioridade da prática agrícola em relação à extrativa, em uma visível demonstração da necessidade de ampliar as áreas de produção de alimentos na província e assegurar a permanência dos colonos nestas áreas de cultivo. Estas questões a serem desveladas, se constituem, portanto, como necessariamente importante para entendermos o processo de formação de um discurso que apresenta a educação como estratégia de civilizar as populações rurais amazônicas.

Palavras-Chave: Escola Rural, Pará, Século XIX.

\section{WHEN EDUCATION CIVILIZATION: PROPOSITIONS ABOUT RURAL SCHOOL PEDRO II (PARA, YEAR 1860)}

\begin{abstract}
The purpose of this paper is to analyze the deployment process of the rural school D. Pedro II, established in provincial farm Pinheiro, near Belém, as a major "achievements" of Pará government, when it came to developing and prosperous future of agriculture in the Amazon region and the so- called "civilization of rural habits". This School marked a clash between customary actions of the settlers and the discourses of civility undertaken by the provincial government, which had in the administrative structure of the school its most direct representatives. Thus, the school was used as an instrument for the defense of values and interests of the provincial government, since the propositions for this space positioned the institution of agricultural education to disseminate ideas about the superiority of agricultural practice in relation to mining in a visible demonstration of the need to broaden the areas of food production in the province and ensure the permanence of the settlers in these growing areas. These issues to be discussed, if so, how are necessarily important to understand the process of formation of a discourse that presents education as a civilizing the rural Amazonian populations strategy.

Keywords: Rural School, Pará, XIXth Century
\end{abstract}




\section{Justificando a criação de uma escola agrícola}

O pensamento do legislador, dizia o presidente do Pará Ângelo Thomaz do Amaral, ${ }^{3}$ manifestado nas leis $n^{\circ} 372$ de 18 de outubro e $n^{\circ} 379$ de novembro, no artigo 31 , parágrafos $2^{\circ}$ e $6^{\circ}$, ambas de 1860 , era dar ao ensino agrícola a importância devida, pois se tratava de oferecer um modelo de educação compatível com as circunstancias das províncias do Norte do Brasil. ${ }^{4}$

Ao evocar a legislação que assegurava a criação de escolas agrícolas na província do Pará, Thomaz do Amaral, um entusiasta da possibilidade de se transformar as terras amazônicas em grandes áreas de produção de alimentos, destacava que a intenção do legislador se somava aos interesses dos proprietários rurais paraense de "tirar a agricultura da rotina que a entorpecia", e com isso promover o desenvolvimento da lavoura da canade-açúcar, o seu fabrico e a criação de gado, "para o que seria tão própria a região". 5

A tarefa a ser seguida a partir da publicação da nova legislação, destaca o entusiasmado presidente, era executar a vontade dos proprietários paraense representada pelas leis em defesa da criação do ensino agrícola. Mostrando-se um legítimo representante dos agricultores do Pará, Thomaz do Amaral apresentava a criação da escola rural D. Pedro II, estabelecida na fazenda provincial Pinheiro, nas proximidades de Belém, como um dos grandes feitos do governo paraense, quando se tratava do desenvolvimento e futuro próspero da agricultura na região amazônica.

Algumas situações favoreciam a implantação da escola agrícola na fazenda Pinheiro. No caso, tratava-se de uma área situada na confluência do rio Maguarí com o Guajará, em lugar considerado "aprazível" e "saudável", além do que possuía terras próprias para o cultivo da cana, do cacau, da mandioca e de cereais. Nas suas terras podiam ser observadas grandes extensões de matas para extração de madeira e fundação de uma vasta escola florestal. Os edifícios necessários para o desenvolvimento de algum outro ofício, além da lavra da terra, podiam ainda ser encontrados, como uma extensa olaria, bons barros e excelente água potável, onde os alunos tinham a opção de desenvolver a fabricação de telhas e tijolos. Continuando com sua descrição sobre o local adequado para implantação da futura escola agrícola, Thomaz do Amaral destacava que estava situado a nove milhas de distância por água, e outras tantas por terra, da cidade de Belém, consistia em mais um condicionante favorável para implantação da escola na fazenda Pinheiro, isto porque, não estava afastada dos núcleos urbanos a ponto de que não pudesse mandar diretamente ao mercado da capital os seus produtos.

Mas não era só isso, se pretendia que a fazenda Pinheiro se constituísse em espaço para recebimento de colonos, principalmente estrangeiros, pois, a expectativa era que em breve tempo as terras da fazenda e dos arredores teriam se valorizado o suficiente para que fossem comercializadas. Isto se justificaria, pois, a progressão da escola nela estabelecida permitiria essa valorização, atraindo colonos que buscavam se utilizar dos conhecimentos adquiridos com o ensino agrícola para melhorar suas práticas de cultivo e promover o desenvolvimento de suas propriedades.

Esperava-se que muitos desses colonos, incluindo imigrantes estrangeiros, prefeririam se estabelecer em terras nos arredores da fazenda, dos que em áreas longínquas dos centros urbanos e afastadas de qualquer contato com os núcleos populacionais, onde podiam comercializar parte do que produziam em suas terras. Assim, o governo provincial havia solicitado autorização da Assembleia Legislativa da província para que essas terras 
"fossem divididas e aforadas a quem nelas quisessem se estabelecer, dedicando-se a lavoura da cana, para moerem na fábrica do próprio estabelecimento de ensino". 6

Há de se destacar que outros planos já haviam sido traçados quanto ao uso da fazenda Pinheiro por parte do governo provincial. Pretendia-se no principio fazer daquele espaço um depósito de imigrantes, que posteriormente seriam encaminhados para os serviços em obras públicas, núcleos coloniais e propriedades particulares. "Ultimamente este espaço tinha sido arrendado com prejuízo do tesouro provincial, posto que os arrendatários deixaram em péssimo estado de conservação", dizia Thomaz do Amaral. Devido essas experiências, o entendimento era de que esta propriedade não convinha ser alienada, pois com a implantação da escola rural teria suas terras valorizadas por conta dos investimentos desprendidos pelo governo. ${ }^{7}$

Prevendo a possibilidade de uma corrente de imigração, foi disposto no regulamento que assegurava a implantação da escola, que os estrangeiros que se encaminharem para o país, na intenção manifesta e decidida de se dedicarem a lavoura da cana, poderiam permanecer na escola rural alimentados, tratados nas moléstias e aproveitados nos respectivos trabalhos, até que encontrassem ocupação. Foi disposto ainda pela administração provincial que o diretor da escola se obrigasse a levantar um plano e organizar o orçamento para construção da estrada de comunicação entre a fazenda Pinheiro e a cidade de Belém, e depois de aprovada pela presidência, começar a sua abertura com os recursos do estabelecimento e com as consignações que a Assembleia Legislativa votasse. E por esta ocasião, verificar quais os terrenos devolutos existentes na direção da estrada e à margem do rio Maguarí, que pudessem ser utilizados como espaço para abrigar esses novos colonos que chegavam ao Pará.

Outras propostas de locais para implantação de escolas agrícolas eram recebidas pela presidência do Pará. Como exemplo a proposição do coronel José do Ó de Almeida que disponibilizava a fazenda Nossa Senhora do Ó, na ilha das Onças, próximo a capital do Pará. De acordo com o coronel, a implantação da escola neste local se justificaria, pois, os alunos poderiam aproveitar as experiências de colonos que ocupavam, através de arrendamento, parte das terras da fazenda com cultivo de alguns produtos, principalmente da cana. Além disso, destacava que a fazenda disponibilizava de engenho para preparação de aguardente e açúcar. Outra proposta era do cidadão Bruno Álvares Lobo, que disponibilizava uma de suas chácaras, a de São João, arredores de Belém, com o mesmo fim, mediante aluguel anual de 6:000\$000, embora prometesse reduzi-lo. Para responder negativamente às propostas, o governo buscou considerar que um estabelecimento tal qual seria a escola D. Pedro II, na medida em que se desenvolvesse, fazia do solo "dispendiosos melhoramentos", e por isso não podia deixar de ser fundado em propriedades públicas. ${ }^{8}$

Considerando as diferentes justificativas para criação de uma escola agrícola em terras paraense, apontamos inicialmente que a proposta deste texto é analisar o processo de implantação da escola rural D. Pedro II. Esta será entendida no contexto de criação dos estabelecimentos de ensino agrícola no Brasil e que se justificava pela necessidade de combate a agricultura rotineira, caracterizada pela queima e derrubada da mata, assim como de uma produção voltada para o consumo familiar.

Como estabelecimento especulativo, esta escola estava envolta de um programa de educação que tinha como princípio a afirmação de uma nacionalidade, disseminação de valores associados à ideia de civilização, assim como a necessidade de suplantar os costumes agrícolas indígenas, concebidos pelas autoridades imperiais como selvagens e não condizentes com os valores adotados pela sociedade moderna. Neste caso, a escola rural D. Pedro II e os discursos de valorização da agricultura em detrimento de outras atividades econômicas, a exemplo do extrativismo, serão analisados no contexto dos 
projetos educacionais rurais e que tinham como propósito, desenvolver experimentos e observações sobre a agricultura da província e sobre os meios de melhorá-las, assim como de aproveitar e aperfeiçoar os produtos agrícolas, e inspirar a população à vocação para a vida agrícola.

Para analisar a proposta de implantação da escola rural D. Pedro II, faremos uma leitura dos relatórios da administração do governo imperial, em especial do ministério da Agricultura, Comércio e Obras. Enquanto espaços de registros de propostas e de manifestação das opiniões dos ministros, esses relatórios serão analisados para compreendermos o entendimento do governo quanto às ações educativas agrícolas e a própria avaliação dos administradores do Império quanto às políticas de educação rural (CHRISTILLINO, 2011, p. 213-216). No caso dos relatórios e pronunciamentos das autoridades provinciais, estes permitirão, além de outras discussões, investigar os debates em torno da implantação da escola rural D. Pedro II. Importante destacar que esta documentação se caracteriza quase sempre como um balanço anual ou de governo, feito no término de um mandato e no início de outro. Não resta dúvida de que expressa a imagem que cada governante teve de seu mandato, e consequentemente de si mesmo (MACHADO, 2011, p. 203-206). Nesse sentido, não se analisou essa documentação como descrição fiel dos problemas e das realizações governamentais, mas como textos que evidenciam, entre outras coisas, embates entre grupos políticos.

Outras fontes veem colaborar para entendermos o processo de implantação da escola rural D. Pedro II são os jornais. A imprensa tornava-se espaço privilegiado para as discussões e posicionamentos políticos quanto às questões que surgiam no país. Assim, estes periódicos foram analisados como lugar de produção de noticiais e local de construção de estratégias de poder. Seus registros são compreendidos como objeto de intervenção num debate político, ou seja, defendem um posicionamento político num certo contexto específico (SANTOS, 2011, p. 185-195).

\section{Escola agrícola, combate a uma agricultura rotineira}

Como estabelecimento especulativo, afinal criavam-se expectativas em torno da educação rural no Pará, a escola rural D. Pedro II surge com o propósito de se constituir como espaço em que se construiria novas experiência de cultivo que combatesse o que então se chamava de agricultura rotineira. Nesse caso, por agricultura rotineira, primitiva ou rudimentar, expressões comumente utilizadas na época, se entendiam as práticas de cultivo caracterizadas pela queimada e derrubada da mata e que foram herdadas das populações indígenas pelos primeiros colonizadores europeus que ocuparam a região ainda no período colonial (LOURENÇO, 2001, p. 12-13).

Esse combate à agricultura herdada dos povos indígenas se materializaria com a criação de métodos modernos de plantio da cana-de-açúcar e o fabrico deste produto, que podia resultar no próprio açúcar ou aguardente. No entanto, não se excluiria quaisquer outras culturas, sejam elas principais (a exemplo da cana) ou acessórias (como o feijão e o milho), desde que, além de lucrativas, pudessem ser ensinadas.

Ainda como escola experimental devia, sem prejuízo de seu fim especulativo, fazer experiências e observações sobre a agricultura da província e sobre os meios de melhorá-las, assim como de aproveitar e aperfeiçoar os produtos por ela fornecidos. Finalmente em sua missão de propaganda, a fim de inspirar a população à vocação para a vida agrícola, coordenaria essas experiências e observações, e as notícias consideradas 
mais importantes para o fomento à agricultura, seriam publicadas em um periódico intitulado Annaes da escola rural de D. Pedro II.

Considerando o regulamento de implantação da escola agrícola, de 01 de maio de 1861, a escola compreenderia uma pequena fábrica de açúcar, que atenderia a demanda produzida no próprio estabelecimento, assim como os pequenos produtores da região. As áreas de cultivo seriam divididas em partes proporcionais à importância comercial de cada cultivo. Nesse sentido, haveria dois espaços de produção agrícola, o que se cultivava as plantas principais, no caso a cana, que teria como destino principal a comercialização, e os espaços das culturas acessórias, como a mandioca, feijão, arroz e outras plantas em que se desejava experimentar o seu cultivo na região, sendo estas mais voltadas para o consumo da própria fazenda.

O regulamento de implantação da escola previa ainda a necessidade de áreas de plantio, onde deviam ser compostas de hortas, jardins, pomares e prados de experimentações. Podia se registrar ainda uma escola florestal para estudos das árvores encontradas nas terras amazônicas e um campo de gado vacum, cavalar e de outras espécies de animais, de raças aperfeiçoadas, tanto para uso do estabelecimento, para estudo da zootecnia, como para fornecimento dos criadores que deles pretendessem fazer aquisição.

No interior da fazenda havia oficinas imediatamente indispensáveis à lavoura e ao fabrico de instrumentos e máquinas aratórias mais usuais, assim como objetos de trabalhos mais rudimentares, como terçados (facões), enxadas, facões, foices e ancinhos (usados para juntar palhas e fenos). Uma escola de instrução primária era também observada. No espaço escolar os educandos desenvolviam o ofício de leitura, a medida do seu adiantamento, tendo como temáticas os rudimentos de agricultura e os princípios que pontuavam a atividade agrícola como a mais importante das tarefas. Como atividade própria da sala de aula se aproveitava para apresentar as conferências teóricas e desenvolver o ensino religioso e moral. Registrava-se também uma biblioteca, com livros específicos sobre a agricultura e administração de estabelecimentos agrários, uma sala de exposição para amostragem dos experimentos que fossem desenvolvidos pelos alunos e um depósito de máquinas e instrumentos aratórios para uso do estabelecimento e fornecimento dos lavradores que os requisitassem.

A implantação desta escola agrícola surgia em momento de entusiasmo do ministério da Agricultura com a defesa do ensino agronômico no país. Conforme registra o relatório do ministério de 1861, teriam sido implantados quatro associações rurais, respectivamente, na Bahia, Sergipe, Pernambuco e Rio de Janeiro, sendo que um dos compromissos dessas entidades era a "criação de escolas normais de agricultura". 9

No Rio de Janeiro, por exemplo, o relatório de 1861 do ministério da Agricultura evidencia a criação em 8 de julho de 1860 do centro de estudos denominado: "Imperial Instituto Fluminense", contando com o auxílio do Estado imperial, que lhe encarregou a administração do Jardim Botânico da lagoa de Rodrigo de Freitas com o intuito de construir um complexo modelo de pesquisa e educação agronômica. ${ }^{10} \mathrm{De}$ acordo com Mary Del Priori e Renato Venâncio (2006, p. 177-178), a princípio, a estruturação projetada pelo governo seria de fundar um estabelecimento rural que pudesse servir de modelo e de escola prática de agricultura.

Estes estabelecimentos de ensino se propunham então, conforme defendia o próprio ministério, a "regenerar" a mão-de-obra do campo, tanto no que dizia respeito aos efeitos negativos da escravidão, quanto ao desejo de que novas técnicas de plantio fossem desenvolvidas, a ponto de expandir as áreas agrícolas não apenas do ponto de vista territorial, mas de implementos e máquinas (DEL PRIORE \& VENÂNCIO, 2006, p. 176). 
Há de se considerar que as propostas em defesa do ensino agrícola remetiam ao período colonial, quando foram criadas sociedades científicas que formataram estudos de ciências naturais e pesquisa agrícola na cidade de Salvador em 1759, sob influência do conde dos Arcos. No Rio de Janeiro em 1772, através da gestão governamental do marquês do Lavradio, fundador da Academia Científica, "cujo objetivo era estudar medicina e botânica, além de investir na produção de anil", outras pesquisas votadas para o conhecimento agrícola foram desenvolvidas (DEL PRIORE \& VENÂNCIO, 2006, p. 104).

A vinda da família real para o Brasil em 1808 também influenciou na valorização dos estudos sobre agronomia, especialmente quando a Corte cria o jornal O Patriota, divulgador de notícias do universo agrícola e principalmente com a construção de duas instituições: O Museu de História Natural e O Horto Real ou Jardim Botânico, responsáveis por estudar plantas de valor comercial.

Posteriormente registra-se em 1864 a criação do periódico Brasil Agrícola, publicado em Pernambuco e em circulação até a década de 1880. Em 1874, registram-se os primeiros números do tabloide $O$ Crepúsculo, periódico de ciência, agricultura, indústria, literatura e notícia, publicado no Pará. No ano seguinte, surge a lume Aurora Brazileira, que tratava de assuntos ligados a engenharia, mecânica, ciências, artes, agricultura e manufatura, curiosamente impresso em Nova Iorque. Entre 1880 e 1890, registra-se a circulação do Jornal do Agricultor, editado no Rio de Janeiro. Todos esses periódicos demonstram, em suas matérias, certo consenso na luta contra a rotina dos trabalhos agrícolas tradicionais e a necessidade de incentivo ao ensino agrícola no país, como estratégia de superação deste tradicional cultivo (DEL PRIORE \& VENANCIO, 2006, p. 185-186).

Ainda como iniciativa aos estudos de agronomia, Dom João se preocupou com a criação de escolas de agricultura, provavelmente sob inspiração da ideologia iluminista em que fora educado, combinando com a necessidade bem prática e imediata de adaptar o Brasil à sua nova condição no cenário mundial, ou seja, sede da Monarquia portuguesa (CAPDEVILLE, 1994).

A advertência do governo provincial quanto à criação da escola rural D. Pedro II, parece antecipar que o novo estabelecimento, embora fosse fundado seguindo inspirações que remetiam à criação dos primeiros institutos agronômicos do país e até as iniciativas de promover a agricultura no Brasil, mesmo em tempos coloniais, teria características diferentes quanto a essas experiências. De acordo com Ângelo Thomaz do Amaral, a escola rural no Pará não teria sido modelada, nem podia ser, por nenhum dos grandes institutos agronômicos que existiam "nos países de adiantada civilização", ou mesmo do Brasil; nem tão pouco "pela simples fazenda normal, em que apenas se aplicavam os processos e as máquinas que a experiência mais teria recomendado, sem entrar em nenhuma indagação teórica". ${ }^{11}$ Desta forma, a escola D. Pedro II se caracterizaria como instituição primária de agricultura, mais prática do que teórica, mais especulativa do que experimental, e destinada a formar trabalhadores, operários, feitores e administradores para os estabelecimentos rurais da província e de outras regiões se assim o desejassem. Ligaria os educando primeiramente a prática dos trabalhos, no entanto ensinaria a ler, a gravar logo na memória os princípios da agricultura, e no campo dos trabalhos, mostraria a aplicação desses princípios.

Assim, o ensino proposto tinha como objetivo profissionalizar e melhorar a atuação das classes dominantes no campo, qualificando o proprietário ou possíveis funcionários. Neste aspecto, o Estado oferecia essa categoria de ensino em nível secundário, sendo que a formação estava voltada para a constituição, não necessariamente de agrônomos técnicos, como previa outras escolas de agricultura do país, mais 
disseminadores de outras experiências de cultivo que dissociassem das práticas então desenvolvidas na província e que eram classificadas como rotineiro cultivo. No entanto, previa que o campo de atuação destes alunos estava focado na execução de tarefas que exigiam certa competência técnica, como orientação das plantas a serem cultivadas, tipos de solo e vegetais formadores da flora da região. Também não deixava de apontar que esta atuação poderia está voltada também para administração empresarial no interior das fazendas e indústrias rurais. De acordo com Mara Regina M. Jacomeli e Rodrigo Sarruge Molina (2010, p 11), no geral, estas instituições formadoras tinham uma concepção pedagógica baseada no método intuitivo, sob inspiração estadunidense e francesa e projetavam um ensino profissionalizante, onde as atividades teóricas eram minoritárias e os exercícios práticos majoritários.

Importante destacar que um dos primeiros projetos de ensino profissionalizante se deu no Estado das Minas Gerais no ano de 1867, porém torna-se realidade somente em 1869 com a institucionalização da Escola Prática de Agricultura de Juiz de Fora. Este centro agronômico tinha como principal objetivo instruir os jovens, principalmente filhos de imigrante alemães, com os mais variados conhecimentos médios das ciências agrícolas, articulando o ensino teórico com o prático. No entanto, seguindo o destino de muitas escolas agronômicas da época, tratou-se de uma experiência de pequena duração, esgotada pela pouca procura (YAZBECK, 2003, p. 101).

Portanto, o formando desta escola deveria se constituir como uma espécie de gestor e promotor do capital agrícola (agroindustrial), atuando como proprietário ou funcionário de modernas fazendas e indústrias, preocupando-se principalmente com as formas de plantio, as técnicas utilizadas e os produtos cultivados, de forma a tornar esta produção a mais rentável. Assim, o profissional formado por estas instituições deveria administrar os complexos produtivos empresarialmente e modernizar todo o sistema com os equipamentos mais avançados, como máquinas (arados e beneficiadores de grãos), insumos (adubos, fertilizantes) e treinamento ou contratação de mão-de-obra especializada. Independente do grau de ensino, nestas instituições os proprietários do século XIX preparavam nelas os seus peritos industriais, da mesma forma que os comerciantes do século XVI preparavam nas suas escolas comerciais os seus peritos mercantis (CAPDAVILLE, 1991, p. 236).

Quanto à escola rural D. Pedro II, o regulamento considerando os fins e organização deste estabelecimento, previa que o ensino prático-teórico abrangeria o ensinamento da agricultura em geral, principalmente a defesa do cultivo como capaz de assegurar bons rendimentos aos cultivadores, possibilitar a posse da terra e a extração das inesgotáveis riquezas que produziam o solo amazônico. No caso, se valorizaria a cultura da cana e o seu fabrico, o que se justificava pela capacidade de rendimento deste produto no mercado europeu, associado às boas condições das terras da Amazônia para este plantio. ${ }^{12}$

Também era objeto de estudo a silvicultura, destacando o conhecimento sobre as árvores de madeiras mais preciosas, ou seja, aquelas consideradas úteis à tinturaria, a marcenaria e a construção civil e naval. Assim se deviam estudar os tipos de plantas úteis, o que justificaria a sua importância e como melhor aproveitar este produto, quando do processo de extração. Dos produtos espontâneos da floresta, as observações se voltavam para os cuidados com o melhor modo de fazer a sua colheita, o momento da coleta e os instrumentos utilizados nesta tarefa. Não se descartava também a verificação das possibilidades de cultivo desses produtos. ${ }^{13}$

Acrescentava-se ainda no currículo da escola o estudo da zootecnia, em especial o conhecimento das espécies bovina e cavalar do país, dos meios de conservá-las e melhorálas. Advertia-se ainda para a verificação das raças que melhor se adaptariam as condições 
da região e que melhor pudessem ser aproveitadas pelos proprietários, não apenas do ponto de vista da criação, mas também do uso desses animais nas tarefas agrícolas. ${ }^{14}$

Da economia rural se estudaria as regras para fundação, organização interior, administração e custeamento dos estabelecimentos rurais e suas relações com o mercado. ${ }^{15}$ A ideia era que os formando tivessem condições de montar e direcionar fazendas, sítios e outros espaços de produção agrícola e de criação de animais.

Conforme a Lei $\mathrm{n}^{\circ} 372$ de 18 de outubro de 1860 que, de acordo com o que foi observado autorizava o governo a criar um estabelecimento agrícola que servisse de escola teórica e prática, previa ainda que fossem admitidos de preferência órfãos desvalidos, filhos de escravas alforriadas e colonos de pouca posse, como alunos internos e outras pessoas que desejassem se instruir, como externos. Incluía-se ainda, entre os possíveis alunos da escola rural, crianças indígenas. Neste aspecto, ao atentar para o atendimento desta clientela, não se estava visualizando a possibilidade de formação de administradores para as fazendas ou outros estabelecimentos rurais, mas implicava na formação de indivíduos que não somente atentassem para o conhecimento dos direitos e deveres da população livre, como era defendido pelos agentes educacionais, mas também fossem capazes de reproduzir esses valores.

A ideia era que os lavradores encaminhassem seus filhos para o internato, como era de se esperar, proporcionando assim a educação que devia ter o homem que se dedicava a vida no campo. A expectativa era que, na medida em que houvesse um crescimento dos lucros da escola, aumentasse o número de internos de modo a poderem ser ali recebidos todos os jovens, incluindo indígenas, fornecidos pelas autoridades competentes, dentre em poucos anos se espalharia pelo interior da província uma mocidade convenientemente preparada para criar as condições para desenvolver a agricultura e superar o abatimento a que se achava.

Como identifica Irma Rizzini (2004, p. 23), na região amazônica, a educação é acompanhada de uma perspectiva de sedentarizar a população do interior das províncias do Pará e Amazonas. Tratava-se, segundo esta autora, de necessidades reclamadas pelos administradores locais, o que estava associado à ideia de desabituar a população local de valores associados em geral às comunidades indígenas. Assim sendo, a escola agrícola D. Pedro II passa a ser pensada como instrumento de combate aos costumes considerados não civilizados e a implantação de novos hábitos condizentes com o que se defendia como sociedade moderna, e que na agricultura parte da materialização desses valores estava na sedentarização e no uso de outras técnicas e instrumentos de cultivo, uma vez que o homem, como foi apontado anteriormente, com essas novas práticas, deixava a condição de completa dependência dos ritmos da floresta para se tornar produtor de seu próprio alimento.

Prosperidade e civilização eram expressões que adquiriam um forte simbolismo nesse momento, e nesse aspecto a educação agrícola deveria se constituir como instrumento capaz de assegurar que esses valores fizessem parte dos interesses dos grupos sociais na Amazônia. Neste aspecto, a escola rural D. Pedro II teria em um primeiro momento a função de afirmar os valores morais e religiosos, não sendo de forma gratuita a presença de um capelão no quadro de pessoal da escola. Conforme regulamento da escola os trabalhos de inspeção, fiscalização, direção, administração, instrução e custeamento da escola incumbia ao presidente de província e ao seguinte quadro de pessoal que atuaria diretamente na escola: uma comissão fiscal de cinco membros, um diretor, um administrador, uma capelão, um médico, um guarda e aos feitores, mestre de oficinas, serventes, e trabalhadores extraordinários que fossem necessários. No caso específico do capelão caberia a este "celebrar os ofícios divinos dentro do estabelecimento, servir de 
bibliotecário, dirigir a escola de instrução primária, principalmente quanto à leitura dos rudimentos de agricultura e princípios morais e religiosos". ${ }^{16}$

Outra função, a qual justificaria a própria criação da escola era de que esta podia servir para combater aquilo que se convencionou chamar de "vida ambulante" dos povos amazônicos, numa referência aos constantes deslocamentos das populações pelo interior da floresta. Esta situação que era provocada, como já foi destacada anteriormente, pela necessidade de extração dos recursos naturais, dos quais dependia a sobrevivência dessas populações. Acreditava-se que as crianças com os novos aprendizados no espaço escolar rural, principalmente de valorização da agricultura em detrimento a outras atividades econômicas, seriam importantes elementos de convencimento dos pais a desenvolverem a atividade agrícola, assim permitiriam que as experiência desenvolvidas na escola rural pudesse ser transportadas para as lavouras particulares, dinamizando a produção, aumentando os recursos dos proprietários e assegurando a própria constituição das propriedades com a permanência desses colonos nas áreas de cultivo regular.

Assim, o objetivo da escola rural era educar desde a infância, operários, preparando-os para os trabalhos agrícolas, pois se entendia que a agricultura, se constituía no caminho para a superação da ignorância, miséria e barbárie dos povos da região. Neste sentido, o estado de civilização seria alcançado pela integração à sociedade das populações que viviam nas matas. A noção de civilização apresentava um matiz próprio no projeto educacional, na medida em que, tinha-se a perspectiva de que os povos seriam transformados e adaptados à sociedade moderna, superando a selvageria, compreendida não só pelos costumes não condizentes aos padrões de civilidade da época, mas com a introdução de novas técnicas de produção, que tinha na agricultura, a prática civilizatória ideal.

Ao que tudo indica a "vida nômade" provocada pela extração e fabricação da goma elástica, assim como a colheita de vários produtos, em muito importunara alguns gestores. De acordo com o presidente do Pará Capistrano Bandeira de Mello Filho, ao acusar a população amazônica de viver embrenhada nas matas, destaca que "as vistas do governo a ação benéfica e a regular administração da justiça e dos benefícios trazidos pelas autoridades e pelas ações do governo dificilmente [podiam] chegar". ${ }^{17}$ Para estas autoridades, a atividade regular desenvolvida na escola agrícola em muito podia contribuir ao mesmo tempo para a divulgação e implantação de novas formas de plantio e introdução de culturas com maior concorrência no comércio, também assegurar a valorização da atividade agrícola, uma vez que, um dos propósitos principais destes estabelecimentos era inculcar valores que associasse a agricultura como principal atividade econômica.

Considerando estas questões, diríamos que combater as práticas indígenas era um dos propósitos da escola agrícola D. Pedro II. Esta instituição de ensino marcava um embate entre as ações costumeiras dos colonos e os discursos de civilidade empreendidos pelo governo provincial, que tinha na própria estrutura administrativa da escola seus representantes mais diretos. Assim, a escola era utilizada como instrumento de defesa de valores e interesses do governo provincial, uma vez que este espaço era utilizado para divulgação de ideias quanto a superioridade da prática agrícola em relação a extrativa, em uma visível demonstração da necessidade de ampliar as áreas de produção de alimentos na província e assegurar a permanência dos colonos nestas áreas de cultivo.

Tratava-se, portanto, de um embate entre as representações do que se considerava como selvagem e atrasado e o que era concebido como moderno e civilizado. Os discursos oficiais, quase sempre opunham, quando discutiam a escola rural D. Pedro II, a atividade agrícola da prática extrativa. Nesse caso, recomendavam veementemente o domínio do cultivo sobre a coleta. Estes debates apresentavam um cenário amazônico de luta pelo 
avanço do progresso e da civilização sobre a natureza e a barbárie de seus habitantes, os índios, os caboclos, os mestiços. Esta oposição, guardadas as devidas proporções, não deixava de afetar a educação da população e a solução apontava para aquilo que consideravam como "vitória das armas da vida civilizada".

Como uma ultima observação, é emblemática a fala dos engenheiros Corrêa de Miranda e Gonçalves Tocantins. Estes eram enfáticos na ideia de que a educação rural se viabilizaria por estar voltada para a lavoura. Neste aspecto, a lavoura implicava na mudança considerada fundamental quanto aos hábitos dos colonos na província do Pará, uma vez que para os engenheiros, através da agricultura, estes deixariam a "vida errante" em que estavam habituados. Neste processo de alteração de hábitos e costumes a escola rural D. Pedro II se constituía como uma das principais estratégias não só de convencimento dessa população, mas de fornecimento de métodos e técnicas de cultivo capazes de superar a agricultura rotineira a que estavam habituadas os agricultores do interior da província do Pará.

Referências bibliográficas

BATISTA, Luciana Marinho. Muito além dos seringais: elites, fortunas e hierarquias no Grão-Pará (1850-1870). Belém: Editora Açaí, 2014.

CAPDEVILLE, Guy. O Ensino Superior Agrícola no Brasil. Revista Brasileira de Estudos Pedagógicos, volume 1, número 1, (julho de 1944). Rio de Janeiro: Instituto Nacional de Estudos Pedagógicos, 1944, pp. 229-261. Disponível: http://www.dominiopublico.gov.br/download/texto/me001553.pdf.

DEL PRIORE, Mary \& VENÂNCIO, Renato. Uma história da vida rural no Brasil. Rio de Janeiro: Ediouro, 2006.

CHRISTILLINO, Cristiano Luís. Relatórios Ministeriais. In: MOTTA, Márcia \& GUIMARÃES, Elione. PROPRIEDADES e disputas: fontes para a história do oitocentos. Guarapuava: Unicentro, 2011; Niterói, EDUFF, 2011, pp. 213-216.

JACOMELI, Mara Regina M. \& MOLINA, Rodrigo Sarruge. História da Educação Agrícola no século XIX: Formação gestora e operária no Brasil. In: ROSÁRIO, Maria José Aviz do. O nacional e o local na História da Educação. Campinas, SP, 2010.

LOURENÇO, Fernando Antonio. Agricultura Ilustrada e escravismo nas origens da questão agrária brasileira. Campinas, SP: Editora da Unicamp, 2001.

MACHADO, Marina. Relatório de Presidentes de Província. In: MOTTA, Márcia \& GUIMARÃES, Elione. PROPRIEDADES e disputas: fontes para a história do oitocentos. Guarapuava: Unicentro, 2011; Niterói, EDUFF, 2011, pp. 203-206.

NUNES, Francivaldo Alves. Sob o signo do moderno cultivo: Estado imperial e agricultura na Amazônia. Tese (Doutorado) - Universidade Federal Fluminense, Instituto de Ciências Humanas e Filosofia, Departamento de História, 2011.

RIZZINI, Irma. A união da educação com religião nos institutos indígenas do Pará (18831913). In: Anais do IV Congresso Luso-Brasileiro de História da Educação. Percurso e desafios da pesquisa e do ensino de História da Educação. Uberlândia, 2006, p. 53155325. Disponível: http://www.faced.ufu.br/colubhe06/anais/arquivos/484IrmaRizzini.pdf. 
SANTOS, Claudia dos. Imprensa. In: MOTTA, Márcia \& GUIMARÃES, Elione. PROPRIEDADES e disputas: fontes para a história do oitocentos. Guarapuava: Unicentro, 2011; Niterói, EDUFF, 2011, pp. 185-195.

YAZBECK, Dalva Carolina de Menezes. Formando os bons trabalhadores: os primeiros grupos escolares em Juiz de Fora, Minas Gerais. In: Cadernos de História da Educação $\mathrm{n}^{\mathrm{o}}$. 2 - janeiro/dezembro, 2003, pp. 99-105. Disponível: http://www.seer.ufu.br/index.php/che/article/viewFile/331/322.

\footnotetext{
${ }^{1}$ Texto inicialmente apresentado no IX Jornada do HISTEDBR realizada em Belém em 2010, sendo esta versão revista e ampliada a partir de pesquisas posteriormente desenvolvidas. É resultado de pesquisas desenvolvidas através do projeto "Ocupação de terra, paisagem e produção rural nos Aldeamentos e Colônias Agrícolas do Pará (décadas de 1840-1880)", financiado pelo CNPq.

${ }^{2}$ Doutor em História pela UFF e professor da UFPA

${ }^{3}$ Político atuante na administração imperial, antes de assumir a presidência do Pará, de 8 de agosto de 1860 a 4 de maio de 1861, Angelo Thomaz do Amaral havia atuado como deputado geral pelo Amazonas, além de presidente desta mesma província em 1857, atuado como deputado geral pelo Amazonas, além de presidente desta mesma província em 1857, sendo presidente de Alagoas, de 1857 a 1859 (NUNES, 2011, p. 104).

${ }^{4} \mathrm{Na}$ década de 1860 o Norte do Império brasileiro estava composto por duas províncias, Pará e Amazonas. O Pará representava a principal província da região. Em 1872 apresentava uma população de 275.237 habitantes e uma produção voltada para cultivo do cacau, da cana-de-açúcar e do algodão (BATISTA, 2014, p. 65).

${ }^{5}$ PARÁ. Relatório do Exmo Sr. Angelo Thomaz do Amaral Presidente da Província do Gram-Pará ao Exmo Vice-Presidente Olyntho José Meira por ocasião de passar-lhe a administração da mesma em 04 de maio de 1861. Pará, Typ. de Santos \& Irmãos, 1861, p. 16-17. Disponível: http://brazil.crl.edu/bsd/bsd/u1006/

${ }^{6}$ Idem, p. 13.

${ }^{7}$ Ibidem.

${ }^{8}$ Ibidem.

${ }^{9}$ BRASIL. Relatório do anno de 1861 apresentado a Assembléia Geral na $2^{a}$ Sessão da $11^{a}$ Legislatura pelo Ministro e Secretário dos Negócios da Agricultura, Comércio e Obras Públicas Manuel Felizardo de Souza de Mello. Rio de Janeiro, Typographia Universal de Lamert, 1862, p. 14. Disponível: http://brazil.crl.edu/bsd/bsd/u1946/

${ }^{10}$ Ibidem.

${ }^{11}$ PARÁ. Relatório do Exmo Sr. Angelo Thomaz do Amaral Presidente da Província do Gram-Pará ao Exmo Vice-Presidente Olyntho José Meira por ocasião de passar-lhe a administração da mesma em 04 de maio de 1861. Pará, Typ. de Santos \& Irmãos, 1861, p. 13.

${ }^{12}$ Idem, anexo $\mathrm{n}^{\mathrm{o}} 11, \mathrm{p}$. I.

${ }^{13}$ Ibidem.

${ }^{14}$ Ibidem.

${ }^{15}$ Ibidem.

${ }^{16}$ Ibidem.

${ }^{17}$ PARÁ. Falla com que o exmo Sr. Dr. João Capistrano Bandeira de Mello Filho abriu a 2.a sessão da 20.a legislatura da Assembléia Legislativa da província do Pará em 15 de fevereiro de 1877. Pará, Typ. do Livro do Commercio, 1877, anexo 3, p. XLI. Disponível: http://brazil.crl.edu/bsd/bsd/546/
}

Recebido: janeiro-14 Aprovado: novembro-14 